\title{
Archivo, memoria y dictadura: activistas religiosos y enfrentamiento al régimen dictatorial en Brasil
}

\author{
Archive, memory and dictatorship: religious agents and \\ confrontation with the dictatorship in Brazil
}

João Marcus Figueiredo Assis

Doctor en Ciencias Sociales

Profesor adjunto de la Universidade Federal do Estado de Rio de Janeiro, en la Maestría en Gestión de Documentos y Archivos Coordinador del Grupo de Investigación “Cultura Documental, Religiấo e Movimentos Sociais” jmfassis@yahoo.com.br

Artículo de investigación

Fecha de recepción: 21 de octubre de 2012 • Fecha de aprobación: 30 de enero de 2013

\section{RESUMEN}

A propósito de la investigación sobre el papel de la Iglesia católica contra la dictadura cívicomilitar brasilera entre las décadas de los sesenta y los ochenta, el artículo analiza, primero, las posibilidades teóricas y metodológicas del diálogo entre los documentos y la oralidad para la reconstrucción del pasado; segundo, el estatus científico de la archivología en relación con, tercero, la preponderancia legal del derecho al acceso público a los archivos en un país cuyo gobierno preside hoy una antigua perseguida de la dictadura.

Palabras clave: memoria social, régimen dictatorial en Brasil, Iglesia católica, historia oral, movimientos sociales.

\section{Abstract}

About the research into the role played by catholics Church against the Brazilian civilmilitary dictatorship between the sixties and eighties, the article analyzes, first, the theoretical and methodological possibilities from the dialogue between documents and orality for the 
reconstruction of the past; second, the scientific status of archival, the latter related to third, the preponderance in the legal order has reached the right of public access to the files in a country governed today by a former pursued by that dictatorship.

Keywords: Social memory, dictatorship in Brazil, catholic Church, oral history, social movements.

\section{INTRODUCCIÓN}

Parece que hay consenso en que la religión en Brasil presenta un aspecto inseparable de la constitución social, política, económica y cultural nacional más inclusiva. Siguiendo tal razonamiento, no podemos prescindir del análisis de la sociedad brasilera sin tener en cuenta la presencia de determinadas instituciones religiosas. Queremos analizar aquí un periodo político reciente en Brasil denominado en los círculos intelectuales como Régimen Dictatorial Cívico-Militar, el cual comprende más estrictamente, aunque haya variaciones, los años 1964 a 1985.

De una manera más estricta, nos ceńimos al enfrentamiento de activistas religiosos católicos al régimen instaurado en aquel periodo. El presente artículo es el resultado de informaciones resultantes de nuestra investigación actual sobre la temática. Esa investigación es desarrollada en el conjunto del Grupo Cultura Documental, Religión y Movimientos Sociales, y cuenta con financiación de la FAPERJ. Resaltaremos precisamente los diálogos posibilitados por los encuentros y confrontaciones entre los documentos de archivo y la oralidad en la (re)construcción de los hechos ligados a nuestros declarantes. Ellos pueden ser considerados más que testigos, colaboradores, ya que solamente por intermedio de los recuerdos de sus propias experiencias, algunas informaciones relevantes pueden ser recuperadas.

En la construcción de este artículo, por lo tanto, será fundamental que presentemos el universo de nuestra investigación, sus objetos y objetivos, y las guías en dirección hacia los relatos escritos y orales. Nuestro marco teórico y metodológico sustenta el camino deseado y los resultados esperados. 
Consideramos relevante, por otro lado, identificar elementos que nos ayuden a comprender las relaciones entre documento y oralidad en la consecución de las memorias sobre este periodo. Creemos que, más que contradicciones, la oralidad y la escritura pueden presentar aproximaciones creativas para la construcción de un pensamiento sobre la realidad, donde ninguna de las dos esferas posee la verdad completa.

Apuntamos nuestro análisis más allá de la estrechez de un único campo de sedimentación de las memorias. Por eso mismo, no optamos por una polarización entre lo oral y lo escrito o la sumisión de uno sobre el otro. Sin embargo, en la búsqueda de la comprensión de las diferentes experiencias y el significado de la vivencia religiosa en el desarrollo o en el impulso de lo social y lo político, intentamos organizar las narraciones y sus representaciones hasta aquí presentadas por los entrevistados. Con eso pensamos poder alcanzar la comprensión de sus actitudes en aquel periodo.

La investigación sobre archivos y testimonios apunta a dar continuidad a nuestra perspectiva interdisciplinaria que tiene como interés general las interrelaciones de la Religión, de los archivos y de los Movimientos Sociales ${ }^{1}$. Abordamos los vínculos entre prácticas sociales y universo religioso, especialmente en sus aspectos de la construcción del conocimiento popular por la producción, disponibilidad, circulación, utilización y reapropiación de productos documentales entendidos aquí como una extensa forma de registro de información, tanto institucional como personal o vinculados a prácticas de colectividades de activistas sociales, los cuales constituyen redes de pertenencia y de circulación de conocimientos.

Buscamos investigar aun los referentes institucionales vinculados a la producción, organización y disponibilidad del documento y su importancia social, de forma especial los archivos, en su relación con movimientos sociales y populares, en lo que atañe a los enfrentamientos de activistas e instituciones al régimen dictatorial cívicomilitar instalado en Brasil a partir del año 1964.

1 Tal perspectiva fue iniciada con el Proyecto Archivo, Religión y Movimientos Sociales: Don Adriano Hypólito como modelo identificado católico en Baixada Fluminense-RJ - Financiado por FAPERJ. 
Como perspectiva específica, proponemos como estudio las acciones de activistas religiosos en el enfrentamiento a los aparatos estatales durante el régimen militar. Nuestro esfuerzo es poder comprender cómo las diversas narraciones (documentales $\mathrm{u}$ orales) construyen registros de identidad religiosos alrededor de la figura referencial del compromiso social y sus memorias.

La presencia de sectores de las iglesias cristianas, en especial de la Iglesia católica, se presenta como significativa en el sentido de constituirse, juntamente con otros diversos segmentos culturales, sociales y políticos, como exponente de resistencia al régimen dictatorial.

Nuestro campo de investigación tuvo inicio en la Diócesis de Nova Iguazú, debido a su carácter político-religioso desde los años sesenta y a nuestros abordajes anteriores sobre ese periodo. Sin embargo, nos damos cuenta de la importancia de expansión de ese espacio universal. Volvemos actualmente a la complejidad de formas y grupos de acción que parten o se vinculan al universo católico en Brasil. Percibimos la importancia de los movimientos estudiantiles y obreros, de forma más directa en las acciones en contra del régimen dictatorial.

Nuestra línea de investigación se perfila hacia la identificación de las narraciones sobre la persecución y el enfrentamiento al régimen dictatorial en Brasil y las significaciones presentadas por los activistas en la construcción de elementos de identidad, tanto en lo que se refiere al ámbito personal como al ámbito institucional religioso o socio- político.

Por otro lado se hace necesario investigar conjuntos documentales sobre tales activistas, en especial aquellos producidos por los órganos de represión. Interesa comprender el carácter del control sobre acciones religiosas, culturales, sociales o políticas, imputado al documento del archivo. De esa forma podemos comprender mejor las reivindicaciones actuales sobre el acceso a la información. Es necesario todavía evaluar esa producción y utilización documental tanto personal de dichos activistas, como de asociaciones, sindicatos o partidos, en vista de la comprensión de asuntos ligados al acceso de la información; 
Es fundamental para nuestra investigación abordar la penetración actual de la proyección de las memorias colectivas de ese enfrentamiento sobre las diversas construcciones de identidades personales y colectivas, así como sobre los procesos de solidificación de los Derechos Humanos que surgen.

\section{Archivos y narraciones}

En su trabajo sobre la Iglesia católica y la política en Brasil, Mainwaring (1989), destaca a la Diócesis de Nova Iguazú como ejemplo en el trabajo desarrollado con los movimientos populares. Aunque reconozca el papel de la Iglesia como institución, en ese proceso de estructuración de las luchas populares, resalta, refiriéndose a la Diócesis, que:
El apoyo del obispo a las actividades progresistas en la base fue decisivo, pero son las organizaciones de base y no el obispo los que tienen más importancia en el apoyo a los movimientos populares. Además, fue a través de la capacidad de fortalecer la sociedad civil (especialmente los movimientos populares) y no de sus negociaciones con la elite política local, que la Iglesia tuvo más impacto político (1989, pp. 208-209).

En ese periodo turbulento de la historia del Brasil, el régimen de hecho instaurado en 1964, la Iglesia católica inició un proceso de cambios que la llevó a un acercamiento con los movimientos reivindicativos. Fueron relevantes los espacios de concientización y movilización por medio de diversos trabajos pastorales, como Círculos Obreros, Clubes de Madres, Grupo de Jóvenes, entre otros.

El mismo autor expone además una legitimidad física por parte de sectores de la Iglesia católica, que fue la apertura de espacios de reunión, como salones, iglesias y capillas. Por último, refiriéndose a la Diócesis de Nova Iguazú, cita un apoyo o legitimación moral, por la confiabilidad acreditada a la Diócesis por ser institución, por la presencia de padres en los medios populares y por la acción del obispo ya fallecido don Adriano, que expresaba claramente su apoyo a los movimientos populares. 
A partir de los estudios de las acciones de dicho obispo, entendimos que ellas son ampliadas por la adhesión de diversos activistas religiosos como laicos/laicas, padres religiosos/as. El estudio sobre el conjunto de sus actos nos permite conocer estrategias y tácticas del enfrentamiento al régimen cívico-militar por el sesgo de las prácticas religiosas. También permite comprender la constitución de las memorias sociales (Halbwachs, 1990, 1994; Pollak, 1989, 1992; Pomian, 2000) que contribuyen a la construcción de identidades religiosas, sociales y políticas en perspectiva interrelacionar, en especial en Baixada Fluminense.

Otro aspecto que nos parece importante es el entendimiento de las acciones de control y represión de esas actividades indicadas más arriba, por los aparatos de los órganos de represión. El estudio sobre procesos documentales será imprescindible para ese análisis (Fico, 2008; Antunes, 2008). La necesidad y la urgencia de ese trabajo se encuentra afirmada en la posibilidad de recolectar informaciones en verdad relevantes para la comprensión del sentido de tales acciones, en especial por la edad avanzada de nuestros testigos. De otra forma, los recuerdos de esas personas podrán estar destinados a desaparecer imposibilitando los contactos directos con los testigos.

En ese sentido, el recurso de la historia oral es de fundamental importancia. El diálogo con las narraciones orales y la memoria posibilita no una jerarquización de fuentes, entre lo escrito y lo oral, sino un refuerzo de sus especificaciones y sus aproximaciones. Por lo tanto las memorias de los activistas religiosos revelan en sintonía con las fuentes documentales, un acceso, no solo al pasado, sino a las representaciones sobre dicho pasado, tomando como base las experiencias de los testigos y su lugar en el presente.

Aspecto destacado por Paul Thompson (2002) es el carácter interdisciplinario de la historia oral. Como Grupo de Investigación compuesto por áreas de conocimiento en diálogo ${ }^{2}$, tal metodología posibilita la ampliación del análisis de las conversaciones de los entrevistados. El autor destaca, en su experiencia con la historia oral, la necesidad de atención a los intereses propios de la sociología, de la antropología, de

2 Los componentes del Grupo responsable por el desarrollo de esta investigación pertenecen a diferentes áreas de conocimiento, como Psicología, Sociología, Educación, Ciencia de la Información. 
la historia, de la psicología y psicoanálisis una vez que las narraciones abren espacio para diferentes abordajes sobre las acciones humanas.

La comprensión de la realidad bastante compleja como la de ese periodo histórico brasilero exige una ampliación en las perspectivas de investigación. Verificamos la necesidad de estar atentos a las consecuencias de la perspectiva de tales activistas religiosos, su involucramiento subjetivo en la lucha por la redemocratización política y por la organización popular, así como la constitución de estrategias informacionales vía producción, organización y utilización documental.

Nuestra principal meta es la identificación y el análisis de prácticas y tácticas de activistas religiosos. En la perspectiva de Certeau (1994), las prácticas y tácticas se transforman en modos de constitución de formas de supervivencia en medio de las adversidades cotidianas. Dos referencias serán fundamentales, los documentos y las narraciones. Las acciones de tales activistas religiosos identifican modos de pensar y de adhesión a proyectos reivindicatorios y de cuño crítico en relación al régimen dictatorial. Pensamos que llegar al conocimiento de las intenciones de esos activistas por medio de sus prácticas nos permite relacionar las implicaciones religiosas en la conducción de los movimientos sociales, asociativos y políticos de aquel periodo.

Sin embargo, nuestro objetivo no se destina exclusivamente al marco temporal del periodo dictatorial cívico-militar en Brasil. Por el sesgo de los estudios de la memoria, buscamos relacionar las narraciones y los documentos a la constitución de expectativas en cuanto al presente y al futuro pensando en tales activistas. Sus acciones actuales, compromisos políticos, desarrollo de proyectos sociales, culturales y religiosos deben motivar la reconstrucción de los hechos por medio de sus recuerdos. Por lo tanto, entendemos que la memoria nos permite elucidar aspectos más amplios sobre las identidades construidas por personas y colectividades.

Por el aspecto documental podemos comprender que tales acciones eran representadas, tanto por los activistas involucrados como por las instituciones que los cobijaban: la Iglesia católica por un lado y los órganos de control y represión por el otro. Por lo tanto, el documento, sea entendido más específicamente como archivo o más generalmente como una amplia gama de registros (personales o colectivos), es un 
elemento fundamental para el conocimiento de las estrategias de mantenimiento y duración temporal, tanto del control de actividades consideradas como peligrosas o subversivas como de maneras de articulación e involucramiento en procesos sociales de movilización y concientización religiosa en una perspectiva socio-política.

La investigación sobre los recuerdos de los activistas religiosos sucede, por lo tanto, por medio de por lo menos dos vehículos: los documentos y las narraciones. En el primer grupo están las Instituciones de Archivo que guardan los documentos sobre las acciones de individuos y de colectividades. Tales instituciones serían los Archivos de la Diócesis de Nova Iguazú y de la Curia Arquidiocesana de Rio de Janeiro y el Archivo Público del Estado de Rio de Janeiro. Son igualmente relevantes para nuestra investigación otros conjuntos documentales, como los pertenecientes a las personas, a sindicatos, asociaciones y partidos políticos. Al principio mapearemos los conjuntos documentales existentes en tales instituciones, no dejando de estar atentos a la posibilidad de ampliación de ese marco.

Como segundo vehículo de informaciones pertinentes, tenemos las narraciones de los activistas involucrados, así como de otros activistas con los que hayan tenido contacto, en el caso que sea necesario.

Identificamos en esos dos vehículos nuestros medios principales para la recolección de informaciones. Entre tanto queremos identificar aun otros procesos comunicativos o informativos por los cuales esos datos serán transmitidos, tales como eventos y encuentros de formación, folletos, celebraciones, cartas, informes, diarios, fotografías, entre otros, que se hicieron presentes, en especial a partir de los contactos directos con los activistas entrevistados.

En vista de lo expuesto anteriormente, los procedimientos metodológicos adoptados en esa investigación son principalmente la investigación documental y la historia oral, a partir de la cual echamos mano a la recolección de narraciones orales por medio de entrevistas semiestructuradas. La historia oral es aquí entendida no solamente como instrumento de complementación de la ausencia de los documentos de archivos, sino en una situación de diálogo con ese. Nuestro análisis tendrá en cuenta, sobremanera, la visión de mundo presentada por los narradores a partir de sus impresiones sobre 
la experiencia relatada. En ese aspecto buscamos aproximar más que distanciar las metodologías de la historia oral y de la etnografía.

La recolección de las entrevistas es hecha por medio de la filmación y no solamente por la grabación de voz, dependiendo de nuestras condiciones y de lo que acepte el entrevistado. De esa forma pretendemos ampliar nuestras categorías de análisis incorporando a la narración oral toda la dinámica corporal, como bien lo alertó Walter Benjamín (1986) al tratar del narrador. Las filmaciones y las charlas, siendo que las narraciones orales serán transcritas procurando, siempre que sea posible, la disponibilidad de su contenido vinculado con la imagen filmada.

Nuestra muestra de entrevistados comenzó con la nominación de los principales nombres de activistas religiosos que tuvieron actuación de movilización social y popular durante el periodo dictatorial. Jerarquizamos los nombres en vista de la relevancia de su participación. A partir de un testigo inicial iremos confirmando los nombres del listado, su grado de importancia y, construyendo la red de entrevistados, mapeando de forma más completa los posibles entrevistados. Nuestra encuesta seguirá, por lo tanto, los modelos no aleatorios, sino direccionados por la contribución de los propios testigos.

\section{Documentos y narraciones: aproximaciones por la historia oral}

Las reflexiones intelectuales producidas en la utilización de la metodología de la historia oral nos permiten ampliar el análisis sobre la temática, una vez que se aproxima del universo de archivos por su expectativa documental. Uno de los recursos de análisis en historia oral se encuentra en la producción documental. Por otro lado, o de forma complementaria, la relevancia de la historia oral está en no constituirse en un puro método de producción documental a partir de una "voz verdadera". Esto significa que el foco se encuentra en la producción sobre la visión de mundo de los entrevistados más que en la pureza objetiva de los hechos por ellos narrados.

En este punto nuestro debate se concentra en el cuestionamiento sobre los límites de los análisis de archivadores sobre formas de interpretar o de presentar el mundo sin el interés primario o irremediable de constitución de verdades. En consideración con 
el trabajo de constitución de memorias a partir de determinados grupos o activistas, podemos entender que, algunas veces, la narración está menos interesada en el hecho tomado como verdadero y más en su inscripción en el campo de la reflexión sobre experiencias y vivencias. Sin la intención de la verdad, ¿cómo entender la validez de tales narraciones, si fuéramos llevados por la captura de la veracidad?

El trabajo de investigación sobre el acervo de don Adriano Hypolito nos ayuda a reflexionar sobre tal temática. La utilización de su patrimonio documental potencializa la constitución, mantenimiento y difusión de un ideario católico para Baixada Fluminense. Tal investigación toma en cuenta cómo los activistas directa o indirectamente vinculados a la memoria de ese obispo (re)asumen y (re)transmiten o cuestionan ese ideario.

La archivología es un saber que se compone de prácticas, procedimientos y teorías milenarias, ajustadas, revisadas y aplicadas desde la antigüedad. Sin embargo, tales elementos fueron consolidados en un campo propio de conocimiento a partir de los intereses emanados del nacionalismo y del historicismo del siglo XVIII.

La Revolución Francesa es un marco fundamental para la afirmación del conocimiento de archivista, ya que inaugura, en la era moderna, la conciencia de la accesibilidad a los documentos de interés nacional. En ese periodo se afirma la noción de un Archivo Nacional conteniendo los documentos que ya no representarían una clase privilegiada, de la cual serían su apoyo. Inclusive, aunque tal idea no sea satisfecha en la práctica, los documentos pasan a ser comprendidos como soporte para la consolidación de la ciudadanía, para la constitución de la identidad nacional. Los documentos deben ser entendidos como un patrimonio nacional, al cual todo ciudadano podría acceder para reivindicar o consolidar sus derechos.

Al lado del valor administrativo de los documentos de archivo, consolidado durante milenios, el valor de la prueba (histórica, jurídica, testimonial) pasa también a afirmarse. La archivología, en su inicio y durante décadas, es comprendida como soporte para el conocimiento histórico. Los archivos son entendidos por algunos como un depósito de elementos de valor administrativo o histórico cuyos documentos son fundamentales para la comprensión de la realidad. 
Podemos pensar que una forma de pensamiento positivista presente en diversos campos científicos atribuye a los archivos y a la archivología una función especial en lo que concierne al cuidado de instrumentos para la elaboración de un conocimiento tomado como verdadero y cierto. Tal suceso se debe también a la consolidación de larga duración de la escritura como forma privilegiada de inscripción de la verdad

Por otro lado, pensando en una "historia de los archivos", podemos observar las transformaciones de las prácticas y del pensamiento del archivo conforme a las visiones sobre el documento y sus funciones que fueron siendo modificadas, revolucionadas, transformadas. En la ampliación del concepto de documento, los conocimientos históricos y sociológicos fueron percibiendo los límites del trabajo estrictamente documental, escrito y de archivo. La archivología pasa entonces a percibirse a sí misma en medio de una crisis de sus atribuciones en relación a la custodia documental. Las apelaciones por la disponibilidad y por el acceso documental, las tecnologías de información y comunicación fueron paulatinamente agravando esa crisis.

La archivología contemporánea se encuentra en la búsqueda de soluciones, revisiones y transformaciones de sus marcos teóricos y prácticos para responder a las exigencias del mundo actual. El hacer y el saber tradicional deben ser equilibrados con las exigencias y con las cada vez más rápidas transformaciones. Pensamos que tal vez ese aspecto sea el más impactante, la rapidez con que se suceden los cambios en los diferentes marcos sociales, políticos, económicos, culturales, informativos. Cambios y adecuación a nuevas formas de proceder y pensar la administración de los documentos fue siempre una constante en la organización de los archivos. En determinadas épocas más lentas, en otras más rápidas. Las revisiones y cambios por lo tanto de alguna manera ocurrieron constantemente.

Nuestra preocupación aquí es pensar que las crisis en la archivología ocurrirán con menores o mayores impactos conforme a las condiciones sociales de cada época. Cuando nuevas tipologías documentales exigieron ingreso en el rol de los documentos archivados, tuvieron que ocurrir revisiones y adecuaciones. El cambio

3 Ver Silva, A.M., Ribeiro, F., Ramos, J. \& Real, M.L. (2002). Archivística. Teoría y práctica de una ciencia de la información. Lisboa: Ediciones Afrontamento. 
de actitud de la historiografía en cuanto a los conjuntos documentales relevantes para el trabajo de interpretación del pasado trajeron cambios también en la archivología, área que muchas veces fue entendida como subordinada de aquella. Por lo tanto, una nueva posición frente a los documentos, o al entendimiento sobre lo que debe ser considerado dentro de la conceptualización de documentos trajo también cambios significativos en la actitud de los archivistas. Si no fue por convicción de este profesional, sí entonces por exigencias de los usuarios.

La búsqueda de soluciones a la crisis causada por las nuevas exigencias sociales debe tener cuidado de no descaracterizar el papel del archivista y de los archivos. Sin embargo, además de prudente debe ser audaz en el sentido de entablar diálogos con los diversos campos del conocimiento científico, sin diluirse en ellos. Los segmentos de la archivología que hoy buscan afirmar un carácter de reflexión científica pueden invertir en apoyos teórico-metodológicos que ayuden a ampliar el análisis de su situación social, sus límites y sus perspectivas.

Tomamos como punto de partida de nuestra reflexión el enfoque de Luciana Duranti (1994) sobre las nuevas perspectivas para la archivología contemporánea. Su preocupación con los quehaceres y saberes de los archivos tradicionales apunta a un camino de diálogo de lo contemporáneo con lo tradicional. Entiéndase tradicional, según la autora, como un saber consolidado, al mismo tiempo que pueden ser evaluados nuevamente. Sirve como punto de inflexión. Los conceptos en los cuales los archivistas se apoyan hoy no pierden su validez en medio de las exigencias de la transformación acelerada.

Duranti retoma, por lo tanto, los principales elementos que identifican el documento de archivo, pretendiendo demostrar los recortes necesarios para entender con cuál universo documental tiene que lidiar el archivista. Su preocupación parece ser la de clasificar en qué puntos la archivología se debe fijar para entablar el debate. Las características de organización, veracidad, originalidad, unicidad, autenticidad, se vinculan a las exigencias administrativas para las cuales el documento de archivo se debe reportar. Tal tipología presenta el diferencial archivístico con otros entendimientos sobre el aporte documental. Tales exigencias garantizan la confiabilidad necesaria 
para el testimonio cualificado de prueba documental. Olvidando tales características, el fundamento de archivo sería diluido en nociones amplias por demás.

La preocupación de la autora es la de reafirmar la relevancia de que el archivista continúe comprometiéndose con el cuidado de esos elementos fundamentales para la confiabilidad del documento. Presenta diversos contextos legales donde el documento de archivo, guardadas sus características esenciales, se presenta como prueba de algún acto. Ese parece ser el foco principal de su argumentación, la preservación de la confianza de que el documento de archivo pueda comportarse dentro de los parámetros legales, identificando así su función social.

Su argumentación sigue en dirección a la confusión causada por las transformaciones contemporáneas referente a procesos documentales e informativos. En ese caso es que los procesos y teorías tradicionales deben ser retomados. Sirven como soporte para el debate en el contexto de las transformaciones. Según Duranti, solamente a partir de esa base es posible entablar un diálogo sobre el papel del archivista y de la archivología.

Lo que nos interesa es contribuir al diálogo proponiendo un análisis de las fronteras de la función documental como carácter de prueba para la composición de la investigación de contextos sociales. Estamos interesados en los enfoques donde el documento de archivo dialogue con otras formas de composición de lo real, sin la fijación en los criterios de verdad. La historia oral nos ha permitido evaluar tales condiciones.

Por lo tanto, lejos de proponernos una desconexión entre el documento y la narración, o el abandono de los criterios de prueba documental, presentamos nuestro interés precisamente en las interfaces posibles entre los dos universos de construcción de visiones sobre la realidad. Para eso las relaciones entre fuentes escritas y fuentes orales se hacen necesarias. Conscientes de la imposibilidad de agotar el tema, presentamos algunas propuestas ya adelantadas sobre lo oral y lo escrito.

Llaman nuestra atención las condiciones señaladas por Luciana Duranti para que el documento de archivo pueda ser tomado como prueba en un proceso legal. La 
delimitación de la veracidad del documento es un proceso bastante intrincado y complejo. Las fuentes orales pasan por procesos semejantes de delimitación, tal vez hasta con mayor intensidad. La confiabilidad para con la escritura fue formándose a lo largo de los siglos, especialmente dentro del contexto denominado como occidental. Este acento en la fiabilidad hacia la escritura forzó a la oralidad a tomar un papel secundario y marginal en la construcción de la realidad. Su función terminó por vincularse considerablemente con la personalidad, la intimidad, la subjetividad (Portelli, 2001).

La historia oral, metodología contemporánea de recolección, análisis y teorización sobre procesos narrativos contribuye a evidenciar su carácter social. Obviamente bajo diferentes aspectos, tanto en la narración como la escritura necesitan responder a criterios de confiabilidad, veracidad, manejo, originalidad, recurrencias, etc. Esas aproximaciones pueden llevarnos a pensar más en complementación que en distanciamientos infranqueables. Son formas de construcción social donde sus elementos deben pasar por filtros específicos de verificación.

En lo que atańe a la historia oral, Teresa Haguette (1992) afirma que, como cualquier recurso metodológico, presenta potencialidades y limitaciones. Por encontrarse envuelta en la perspectiva del recuerdo de los testigos, la utiliza "como factor dinámico en la interacción entre pasado y presente, haciendo al aspecto estático del documento escrito que permanece igual a través del tiempo" (p. 93).

Tal dinamismo es justamente tomado como indicativo de la fragilidad de la historia oral. Entre tanto, la autora apunta que ahí también se encuentran sus potencialidades. De la misma forma que el documento, como lo mostrado anteriormente, las narraciones necesitan de atención en cuanto a su contenido ideológico y de manejo.

El punto de confluencia con lo destacado en el inicio de este texto sobre la veracidad del documento de archivo, se encuentra en la perspectiva metodológica de la historia oral. Como afirma Haguette:

Se necesita considerar que la historia oral está preocupada con lo que es relevante y significativo para la comprensión de la sociedad, y no en la 
acumulación anárquica de supuestas piezas de evidencia que no aportan nada a los datos ya existentes (2005, p. 93).

Eso significa que la intención de organizar los datos presentados por los entrevistados, entregando elementos de compresibilidad de lo real mostrado se asemeja a la perspectiva del documento de archivo de la organización de las informaciones registradas.

Las narraciones, por lo pronto, conductoras de intenciones basadas en los "marcos de la memoria", como apuntaba Halbwachs (1990, 1994), no se encuentran presas en necesidades estrictas de objetividad, veracidad y verificación. En la propia intención de manejo pueden ser verificadas las conducciones ideológicas del narrador. Sus planos de presentación de una determinada visión del mundo deben ser comprendidos en el contexto de inserción de sus recuerdos en el plano colectivo. Abren potencialidades en la aprensión del observador sobre las estructuras de lo que está narrando. La historia oral, por lo tanto, no debe ser confundida como una mera técnica de producción de material residual que completará las lagunas documentales. Es un poco más allá de una perspectiva reduccionista del papel de la oralidad. Documento, oralidad y memoria pueden confluir con sus apuntes particulares sobre la realidad reconstruida por la contribución de sus productores y sus analistas.

Tratándose del tema documental, podemos entenderlos como componentes materiales de los recuerdos y de la construcción narrativa. En cuanto a los materiales o soportes de los recuerdos, autores como Pomian (2000), afirman tratarse de vestigios de épocas pasadas elegidas en el presente como contenido de referencias de ese pasado. Vestigios o fragmentos de épocas pasadas no representan, en sí, referencias de recuerdos. El autor ejemplifica con el fósil. Este no pasa de una descomposición y modificación de un cuerpo animal o vegetal. Es el interés del investigador, en el presente, que confiere a tal fósil, un sentido referencial al tiempo pasado.

A tales vestigios se le unirán otros, proyectados, estos sí, para que transmitan a la posteridad recuerdos de hechos, personalidades o acontecimientos. Son los denominados "documentos-monumentos" (Le Goff, 1996; Glènisson, 1961), forjados para que se vuelvan vestigios programados del pasado. 
En el proceso de transmisión de los recuerdos, el lenguaje es un elemento fundamental, siendo considerado como diferenciador principal de la transmisión de los recuerdos entre los seres humanos. Es una de las características de diferenciación de la memoria animal o vegetal transmitida genéticamente (Pomian, 2000).

La memoria transgeneracional es aquella transmitida por medio de las narraciones, vestigios y de los documentos-monumentos. A medida que la narración es substituida por la información (Benjamin, 1986) es que los vestigios, fragmentos o reliquias pasan a ser parte de las colecciones, destacadas de sus funciones de uso y resguardadas de la degradación, se vuelven formas de transmisión selectivas, atendiendo a intereses y perspectivas institucionales de centros o instituciones de memorias, tales como museos, bibliotecas y archivos. Pasan así a ser entendidas como memorias transindividuales, donde los objetos destacados de la experiencia directa de los individuos se remiten a la memoria como estimuladores que se encuentran por fuera de los individuos (Pomian, 2000).

La memoria es entendida por nosotros, pues, a partir de su multiplicidad de posibilidades, como creación, proyección de marcos sociales, transmisión transgeneracional o transindividual. En un momento las narraciones reproducen la perspectiva oficial, en otro son reinterpretadas por las proyecciones subjetivas, y en otro se transmiten por los vestigios y monumentos erigidos y electos a partir del presente para interpretar el pasado.

\section{Archivos del régimen militar en Brasil y el acervo de don Adriano Hypolito, obispo de Nova Iguaçu -RJ}

De entre los vestigios y objetos del pasado destacamos el documento de archivo como elemento fundamental para la reconstrucción del periodo que nos interesa, el régimen dictatorial.

En las últimas décadas, el tema del acceso a las informaciones contenidas en los documentos producidos por los órganos de represión viene ganando presencia. La discusión deja de ser exclusiva de los académicos para surgir en los medios de comunicación social. El investigador Carlos Fico resalta algunas de esos eventos que 
impulsaron la discusión en un ámbito más amplio de la sociedad brasilera. Tales acontecimientos habrían favorecido la discusión sobrela apertura delos documentos de aquel periodo. El primer acontecimiento fueron los procedimientos para la búsqueda del paradero de los restos mortales de los que lucharan en la llamada "guerrilla do Araguaia". Otro acontecimiento fue provocado por la controversia en torno a las indemnizaciones pagadas a los ex-presos políticos. El tercer acontecimiento fue la publicación, por parte de la prensa, de supuestas fotografías del periodista Vladimir Herzog, las cuales habrían sido botadas antes de su muerte a manos de los órganos de represión. Las noticias sobre la quema clandestina de documentos sigilosos en la Base Aérea de Salvador, Bahía, componen ese marco que llevó a discusiones más amplias sobre la necesidad de preservación y acceso a los documentos de archivo. Por último, los debates sobre el alcance de la Ley de Amnistía de 1979, que beneficiaba también a los torturadores, fue otro acontecimiento que contribuyo a incrementar las discusiones (Fico, 2008).

Agregó a este marco la entrada al poder, principalmente en instancias federales, de los cuadros militantes que actuaran en el periodo de represión y que fueron presos y torturados. Posteriormente, con la intensificación de los debates y la presencia de Dilma Roussef en la presidencia de la república, ex-presa política, así como los avances en los caminos legales, llegamos a la publicación de la Ley de acceso a la información (Ley 12.527 del 19 de noviembre de 2011). Actualmente es la legislación con la cual nos encontramos para buscar acceso a los documentos de archivo producidos en aquel periodo. Juntamente a esto fue instalada la Comisión Nacional de la Verdad el 16 de mayo de 2012. Muchas críticas y apoyos se han manifestado a esas dos instancias, lo que ha motivado posicionamientos diferentes y análisis académicos jurídicos y sociológicos.

De cualquier forma es posible, por esos movimientos, comprender la relevancia y la urgencia que revisten los documentos de archivo y las instituciones de custodia actualmente.

Autores como Carlos Fico (op. cit., 2008), no creen que los documentos del periodo dictatorial vayan a aclarar determinados aspectos sobre aquella época, como la expectativa de la opinión pública hace creer en algunos momentos. Por otro lado, los 
órganos dictatoriales en Brasil fueron de los que más documentaron sus actos, lo que favorece la ampliación del conocimiento sobre aquel periodo y, principalmente las posibilidades de confrontación con las narraciones recolectadas hasta el momento.

Otro aspecto importante a ser recordado es que, en 2008, solamente el $5 \%$ de los documentos liberados habían sido estudiados con una perspectiva histórica profesional, conforme a estimaciones de Fico (op. cit., 2008). Ese aspecto nos lleva a un sinnúmero de posibilidades de nuevos descubrimientos y de revisiones sobre los acontecimientos. Los documentos administrativos, sin relaciones directas con las persecuciones o con las torturas pueden, a su vez, ser importantes en la claridad de rutinas administrativas de los órganos dictatoriales y de sus activistas.

Los documentos de archivo sobre el régimen dictatorial pueden todavía esclarecer sobre las divisiones internas del régimen, demostrando la heterogeneidad entre los grupos. Ayudan también con la confrontación de los recuerdos sobre el periodo.

Tal vez más importantes, dichas investigaciones han servido para que la historia del periodo enfrente asuntos delicados, notoriamente cuando se confrontan con los recuerdos sobre el periodo, como es el caso de la responsabilidad, siempre negada, de los oficiales-generales por la tortura y por las muertes de prisioneros, o de la inexistente relación de causalidad entre el endurecimiento del régimen y la opción de la izquierda por la lucha armada (Fico, 2008, p. 76).

La complejidad de la red de archivos en Brasil, además de sus relaciones con las divisiones político-administrativas, demuestra la importancia de los documentos en el proceso informativo y de memoria. Tenemos todavía los archivos privados de interés público y social y la existencia de fragmentos de acervo público en instituciones privadas y centros de documentación relacionados con universidades e institutos de investigación. Motivados por ese aparato documental y la potencialidad de sus usos, el derecho a la memoria se vuelve hoy parte de los derechos del hombre, en una perspectiva más amplia que la de la ciudadanía (Antunes, 2008):

Con la transición democrática, los archivos de los organismos de represión se volvieron una fuente singular, como testimonio de la actuación de tales 
entes al servicio del Estado autoritario. Las informaciones contenidas en estos acervos demuestran prácticas que fueron usadas en el ejercicio de las actividades represivas. En los tiempos actuales, sirven como instrumento esencial para el fortalecimiento de nuevas relaciones sociales y, consecuentemente, para la consolidación del proceso democrático (p. 15).

Tratándose del proceso de búsqueda y recolección de los documentos del periodo dictatorial por vías legales, Ishaq y Franco (2008), presentan el resultado de investigaciones sobre los órganos de información, identificando sus diferentes funciones y el progreso y cambio en la recolección y utilización de las informaciones. Muestran que había intenso intercambio de informaciones entre esos órganos. Por lo tanto, podemos comprender la relevancia del contacto con esa documentación. Las principales dificultades son los órganos que afirman desconocer el paradero de documentación, órganos que afirman haber destruido sus documentos, siendo que estos mismos órganos no presentan ningún informe sobre el hecho o los términos de la destrucción. La no localización de los acervos de los servicios secretos de las fuerzas armadas, por ejemplo, representan una importante laguna, la cual debe ser llenada (Ishaq y Franco, op. cit., 2008).

Recuerdo aquí países como Uruguay y Perú, donde la historia oral y las declaraciones fueron fundamentales para suplir la ausencia de documentos. Fueron importantes para la reconstrucción de los hechos sobre aquel periodo.

Nuestro interés por la actuación de los activistas religiosos en el enfrentamiento al régimen dictatorial, pasa por la comprensión de la importancia de la reconstrucción de los relatos y de la producción y organización de documentos para la preservación y difusión de las memorias sobre el periodo.

\section{Memorias de enfrentamiento: religión y militancia; formación y conciencia política}

El acervo de don Adriano Hypolito en Nova Iguaçu, el cual viene siendo estudiado por nosotros desde el 2009, es un ejemplo de constitución deliberada de memorias. El mismo está compuesto por fotografías, cartas y recortes de periódicos producidos 
o recolectados a lo largo de los años en que pasó por la Diócesis. El incentivo para la constitución del archivo y el apoyo dado a su organización nos hace posible comprender la importancia atribuida a él.

Además de constituirse en relato sobre el periodo, donde sufrió persecución, secuestro y tortura psicológica, el patrimonio es una posibilidad de constitución de su identidad proyectada para el cuidado de la fidelidad de los adeptos en la militancia por los derechos humanos y por la organización popular.

El propio don Adriano fue el que creó el archivo de la Diócesis. Destinó todo un piso del edificio de la Curia Diocesana para sus instalaciones. El obispo actual también parece apoyar la existencia del archivo, no dejó de reservar un piso entero para este, con el cambio de la Curia para una nueva sede. El responsable por el archivo dice haberse impresionado con el hecho, pero presenta una justificación a partir de su visión:

Don Adriano fue el tercer obispo de Nova Iguazú. Él tuvo un papel muy importante. Él creó el archivo. Todo ese piso aquí fue destinado a ser el archivo, lo que es algo muy raro aquí en Brasil, un obispo, que en un edificio administrativo reserva todo un piso solo para ser un archivo, eso es raro (...).

Nos vamos para la nueva sede, toda la Diócesis, toda la Curia. Nos vamos para Moqueta, otro barrio. Este edificio va a ser alquilado. El archivo va a ser la misma cosa que aquí, un piso entero del edificio como aquí, todo un piso.

Entonces, allá también va a ser la misma cosa, todo el piso, porque el quinto [piso] no funciona, entonces va a ser la misma cosa, va a ser el cuarto piso de un edificio. Va a ser un espacio grande también. Aunque mucha gente de la Diócesis no sabe de la existencia del archivo...y es muy cuestionado también... ¿Por qué es necesario tener un archivo con dos empleados? ¿Quién pagará mi sueldo y el sueldo de G.? ¿Por qué eso? Es costoso. Todavía más en la situación de la Diócesis que tiene dificultades económicas. Entonces es difícil que las personas comprendan eso, que vean que es importante. La ventaja que nosotros tenemos [actualmente], es que tenemos un obispo que 
es italiano, e Italia tiene una tradición en el área del patrimonio histórico. Entonces él tiene esa sensibilidad. Él me pasa todo a mí. Él no me molesta para nada y valora (Declaración del funcionario del archivo, el señor Antonio Lacerda, en entrevista del día 18 de junio de 2012).

Aunque no era italiano ni español, don Adriano Hypolito, en aquel periodo, tal vez haya descubierto el valor de la preservación de la memoria como forma de conservación de la propia identidad de la Diócesis. Tal vez haya proyectado la continuidad de su misión en los recortes guardados, destinados a la perennidad por medio de una institución de memoria: el archivo. Haya tenido o no el obispo tal proyección, Lacerda cree que el Archivo cumple con la misión de ser un guardián de la memoria de la Diócesis. Según él, diversas pastorales, grupos y movimientos recurren a los documentos cuando se lleva a cabo la preparación de algún evento relevante. El recuerdo de algún hecho, la celebración de alguna fecha importante, el refuerzo de algún tema será buscado muchas veces en los documentos guardados en aquel sector de la Diócesis. Para él, el archivo cumple con su misión al:

Preservar la memoria de la Diócesis, la memoria histórica de la Diócesis, subsidiar a la Diócesis en su acción pastoral. Vamos a suponer ahora que hay mucha violencia, que volvió de nuevo, entonces, la Diócesis quiere promover la campaña contra la violencia, entonces en el archivo podemos ver lo que la Diócesis ya produjo en el pasado desde la década de los sesenta sobre la violencia, expedientes, todo. Entonces yo mando ese material para el encuentro pastoral. Cuando una parroquia está cumpliendo cincuenta años, ahí yo hago un documento. A veces un padre muere... Ahora dos padres murieron y nosotros no teníamos nada de la vida de esos padres, porque cuando ellos estaban vivos, yo no podía estar juntando cosas de la vida personal de ellos, solo después de su muerte. Entonces ahora yo tengo que documentar la vida de esos dos padres. El archivo tiene una función pastoral que es estar apoyando a la Diócesis en su acción, la acción pastoral. Entonces esa es la función del archivo, dar apoyo, estar orientando (Ibídem).

Hay también una producción literaria y periodística hecha para circular en los diversos espacios de la Diócesis. Hay columnas en el periódico informativo de la Diócesis, 
el Jornal Caminhando, que posee un cuño memorial, reafirmando los hechos del pasado, los lugares y las personas seleccionadas por su relevancia. Así, un padre que fallece o que celebra bodas de ordenación sacerdotal, un templo considerado como patrimonio cultural de la región, entre otros. La producción mensual del periódico permite seleccionar y difundir material a partir del acervo del archivo. Don Adriano es una figura que prácticamente todos los meses aparece en el informativo.

Partimos de la perspectiva de los documentos de archivo y sus sentidos de existencia y de uso para ampliar el asunto. Por lo que vimos anteriormente, la historia oral posibilita el diálogo con tales documentos en vista de una comprensión más amplia de los periodos, de las personas, de los acontecimientos y de las construcciones de memoria sobre ellos. Las narraciones son fundamentales, pues presentan visiones del mundo por momentos convergentes, por momentos divergentes incluso contradictorias sobre el mismo hecho. Venimos intentando ampliar nuestras bases empíricas para otros acervos documentales y para activistas religiosos diferenciados en términos de experiencias, perspectivas y campos de acción.

Nuestro marco de entrevistados está compuesto por activistas laicos, padres, sacerdotes separados del ministerio y obispos. Todos pasaron, directa o indirectamente, por el enfrentamiento al régimen cívico-militar. Ejercen hoy funciones ligadas a los derechos humanos o formación de conciencia crítica, en partidos políticos, sindicatos, organizaciones no gubernamentales. Estamos tratando con personas que continúan actuando en frentes vinculados al universo religioso y socio-político.

Nuestros entrevistados se encuentran entre los 61 y los 84 años. Componen un marco variado de militancia en las diferentes regiones y diócesis en las que se encuentran, concentrándose en la Arquidiócesis de la Capital y en las Diócesis de la Región Metropolitana de Rio de Janeiro. La recolección de entrevistas, hasta el momento, abarcó un padre, una religiosa, dos laicos y dos ex-sacerdotes.

El padre actualmente es actuante en la coordinación de la antigua Acción Católica Operaria (ACO), hoy conocido como Movimento de Trabalhadores Cristáos (Movimiento de Trabajadores Cristianos) (MTC). El nombre fue cambiado, según él, para abarcar a otros trabajadores vinculados a un universo más amplio 
del cristianismo, no limitándose solo al catolicismo. El entendimiento sobre el trabajador y sus problemáticas y sus reivindicaciones también habrían cambiado. No se identificarían más con el concepto de operarios, prefiriéndose ahora al término más amplio: "trabajador".

Ese padre fue perseguido y preso junto con otros padres y militantes cristianos. Recuerda quién fue el responsable, junto con otros sacerdotes de su congregación, para ayudar a ocultar y huir a la clandestinidad y para el exilio de innumerables individuos perseguidos políticos. La parroquia donde actuaba, servía como escondite para los perseguidos políticos.

La religiosa entrevistada, hoy una señora de ochenta y dos años, actúa en el Movimento de Trabalhadores Cristãos y en el Sindicato das Domésticas. No llegó a ser prisionera, pero tuvo varios miembros de su familia presos, torturados, inclusive uno tuvo que exiliarse y un sobrino falleció a causa de la tortura. Informó que incluso en pleno proceso de redemocratización, su correspondencia estaba siendo vigilada, inclusive abierta y leída antes de ser entregada en su casa. Su familia fue intensamente vigilada durante el periodo dictatorial.

Una laica entrevistada era una joven profesora en aquella época. Cuenta que poco a poco fue envolviéndose en los movimientos reivindicativos por medio del contacto con el obispo de su diócesis, don Adriano Hypolito, con padres y con otros activistas de la pastoral. Tanto ella como su hermano fueron vigilados y abordados por militares en determinados momentos. Resalta haber vivido una mezcla de entusiasmo en medio de la actuación social y de miedo cuando fue abordada directamente por los militares en la tienda de su padre y en la escuela donde trabajaba. Después de que el obispo fue preso y torturado psicológicamente, dejándolo desnudo en una calle desierta de la ciudad de Rio de Janeiro, pintado de rojo en referencia al comunismo y de la bomba colocada en el altar en la catedral de Nova Iguazú, el miedo se intensificó. "Si hicieron eso con un obispo, ¿qué no harían con cualquier otra persona?”, se pregunta la entrevistada.

El otro laico, hoy un señor de ochenta y dos años, aunque no haya lidiado directamente con la persecución del régimen dictatorial, en aquella época fue progresando en 
conciencia política, como él mismo afirma. Eso fue posible debido a su participación con los sindicatos. Como trabajador del comercio, se envolvió desde joven en luchas reivindicatorias. Posteriormente, a partir de un mejor conocimiento sobre la actuación de la Iglesia católica en su región, pasó a acompañar los trabajos de la Pastoral Obrera, integrándola más tarde. Apunta que su entrada en ese movimiento ocurrió después de un curso sobre la Biblia donde se proponía una lectura de las escrituras teniendo como base la realidad social, política, económica donde vivía.

Otro entrevistado había sido religioso, hoy integrante de una organización no gubernamental que desarrolla estudios sobre religión. Su contacto con el régimen dictatorial no pasó por el enfrentamiento directo, debido a las condiciones de su formación religiosa. Se acuerda de algunos momentos de su juventud como estudiante de teología, los cuales fueron significativos. Sin embargo supo de forma nebulosa lo que acontecía en el contexto nacional, algunas noticias sobre persecución y tortura acabaron llegando de forma clandestina por uno u otro compañero de congregación. Recuerda su contacto con algunos religiosos dominicanos que habían sido liberados de la prisión por tener relación con grupos revolucionarios, y que fueron a estudiar en el mismo instituto de teología. Resalta que, incluso así, la realidad de esos exprisioneros políticos pasaba desapercibido para el conjunto de estudiantes. Eran inclusive observados con desconfianza. Otro factor marcado como relevante fue el contacto con el fraile franciscano Leonardo Boff, habiendo terminado recientemente su doctorado en Alemania y traía ideas innovadoras para el estudio teológico, como su vinculación con el análisis social.

Un hecho provocó un cambio en su trayectoria. En un momento dado, después de terminados los estudios y de ser ordenado padre, ocupando el cargo de colaborador en la parroquia donde vivía, resolvió, junto con estudiantes de teología y filosofía y algunos laicos, encabezar una marcha de protesta sobre una situación ocurrida en la ciudad.

Consiguió convencer al párroco de negociar con el obispo una "procesión”. Esa "procesión" escondía la real intención de una marcha reivindicatoria hasta la alcaldía de la ciudad. Todo organizado, al iniciar la procesión comenzaron a aparecer carteles de reivindicación y, a medida que se aproximaban a la Alcaldía, algunas órdenes 
comenzaron a surgir de entre los participantes. Cuando llegaron, el obispo, varios participantes y los militares, descubrieron que se trataba de una marcha. Cuenta que fueron rápidamente cercados por un pelotón militar y forzados a dispersarse.

Lo acontecido le costó a él y al párroco la transferencia. Él fue enviado a Baixada Fluminense. Afirma que allí pudo tener contacto con otro tipo de organización de la Iglesia católica, orientada a la organización popular. Concuerda que de ahí en adelante pasó a conocer y participar de manera directa en los procesos reivindicatorios vinculados a la Iglesia católica.

El último entrevistado fue un religioso que integra también una organización no gubernamental de estudios sobre religión. Su trayectoria se volcó desde temprano a la participación en la Ação Católica pela Juventude Estudantil Católica (Acción Católica por la Juventud Estudiantil Católica) -JEC-. Al principio, en el colegio donde estudiaba, la JEC mantenía un perfil conservador, ritualista y celebrativo. Era más una asociación religiosa y menos un movimiento de reivindicación estudiantil. Más tarde se involucró con la JEC de su diócesis y sintió la diferencia entre las dos realidades. En el contexto descubierto ahora había un nivel de concientización política inimaginable en la JEC de la cual era oriundo. Luego se dio una crisis, pues pasó a llevar para allá las críticas que eran desarrolladas en la nueva instancia de la cual ahora participaba. De ese encuentro, afirma, surgió su tendencia a vincularse a grupos que pasaron de la oposición al régimen dictatorial. Ingresó posteriormente a una orden religiosa junto con diversos compañeros de la JEC diocesana. Allá pasaron a establecer vínculos más estrechos con grupos de oposición, volviéndose el convento donde vivían en una referencia para militantes de izquierda y de la lucha armada. Ese hecho lo transformó a él y a sus compañeros de orden en enemigos del Estado dictatorial y en sospechosos constantes.

Por descuido de las normas de seguridad que circulaban entre los grupos de izquierda, fue preso junto con sus compañeros y torturado durante varios días. Fueron procesados y continuaron presos durante años.

Tal vez sea muy temprano para que hablemos de tácticas y estrategias desarrolladas por esos activistas religiosos, pero es de nuestro interés evidenciar cómo esos activistas 
combinaban trabajo religioso y militancia política y de enfrentamiento. Podemos solamente vislumbrar algunos, una vez que el análisis de las entrevista no se encuentra completa y el marco de entrevistados todavía no está agotado.

Algunos de los entrevistados, al hablar de su periodo en la prisión, agregan gracia y risas a la narración. Otros indican que hoy es posible reír, pero en aquel momento había mucho miedo e incertidumbre en cuanto al futuro. Preferían pensar que aquello iba a pasar y que el contexto iba a cambiar. Pensaban que algún bien debería venir de aquella situación. Estarían promoviendo cambios sociales, por eso era necesario resistir. Uno de los entrevistados habla de la simulación de una enfermedad para escapar de la tortura. Simulaban desmayos después de los choques, alegando que por su edad ya no podían soportar aquellos comportamientos. Entre risas, afirma que eso sirvió.

Otros, hayan sido presos o no, desarrollaron o aprendieron tácticas para continuar haciendo circular información entre los encarcelados y los militantes que continuaban en actividad. Era necesario hacer pasar información para la continuidad de la actuación o de la esperanza de cambio. En ese sentido, cuando no era posible pasar información en trozos de papel enrollados en esferos, las cuales eran cambiadas en la prisión, la memoria debería ser la salvaguarda de esa transmisión. Nos cuenta la religiosa que, al visitar los presos, tenía que guardar todo en la memoria, pues la requisa era severa. Hacía también la transmisión de información entre presos de regiones geográficas bastante distantes.

Incluso, no siendo involucrada directamente con esos grupos, aprendía o reconocía los códigos de seguridad con sus familiares involucrados con organizaciones contrarias al régimen dictatorial. Había seńas, lugares y simulaciones que debían ser aprendidos y seguidos. Podemos todavía comprender como táctica la transformación de lo que antes era pensado como procesiones religiosas y estrictamente espirituales, en marchas de reivindicación y protesta de cuño religioso, al mismo tiempo socio-político.

\section{Consideraciones finales}

Nuestra investigación propone la claridad sobre las prácticas de activistas religiosos en el enfrentamiento al régimen dictatorial cívico-militar en Brasil, especialmente 
contenidos a partir del sentir presentado por los propios testigos para sus prácticas. Buscamos comprender aún cómo los recuerdos sobre ese periodo son re-apropiados para la re-afirmación de la identidad de un tipo de catolicismo vinculado con la organización popular. Sin embargo, no tenemos una consideración a la cual podamos denominar como final, pero sí pistas que nos llevan a la necesidad de profundizar en estos asuntos y a nuevos interrogantes.

El principio de incorporación de categorías reivindicatorias al contexto religioso de esos activistas no posee contradicción. Debido a que todo el proceso por el cual pasaba la Iglesia católica con la apertura propuesta por el Concilio Vaticano II (1962-1965) y por la propia sociedad occidental de un modo general, condujo a muchos religiosos a comprender como parte de su misión el involucrarse con asuntos sociales y políticos más amplios. Debemos comprender que lo religioso no pasaba a ser entendido como menor en relación a lo social y político, es más, parecen retroalimentarse.

El asunto de la memoria es fundamental para esos testigos. Algunos de ellos, en general los laicos, los cuales no participaron directamente de instancias más amplias en la jerarquía católica, se asustan con la relevancia de sus narraciones. Por ello, al ingresar al universo de la entrevista, van ampliando el auto entendimiento de su participación en aquel periodo, redescubriendo hechos y eventos que no habían considerado como fundamentales para la concientización de la participación eclesiástica frente a procesos dictatoriales.

Los entrevistados que ya poseen una trayectoria intelectual académica diferenciada o que estuvieron al frente de organismos sindicales o eclesiásticos, que están acostumbrados a redirigir sus recuerdos sobre esa época o a organizar documentos que traten de acontecimientos sobre la dictadura, presentan narraciones más unidas $\mathrm{y}$, muchas veces, sin grandes sobresaltos. Hay todavía otros aspectos a considerar en la constitución de las memorias, como cuestiones de género, las diferenciaciones profesionales, la diversidad de formación académica, la procedencia y estructura familiar. Todos esos elementos no olvidados en nuestro análisis contribuirán para develarnos no solo lo ocurrido en el periodo dictatorial en Brasil, sino las visiones y narraciones provenientes de las diferentes experiencias particulares y colectivas de esos activistas. 


\section{REFERENCIAS}

Antunes, J. (2008). O Centro de Referência das Lutas Políticas no Brasil (1964-1986): Memórias Reveladas. Acervo: Revista do Arquivo Nacional, 21(2), 13-28, (jul/dez. 2008). Rio de Janeiro: Arquivo Nacional.

Benjamin, W. (1986). O narrador; consideraçóes sobre a obra de Nicolai Lescov. In Magia e técnica, arte e política; ensaios sobre literatura e história da cultura. 2a ed. 197-225. São Paulo: Brasiliense.

Certeau, M. (1994). A invenção do cotidiano: artes de fazer. Petrópolis, R.J: Vozes.

Duranti, L. (1994). Registros documentais contemporáneos. Estudos Históricos 1994/13. Rio de Janeiro: Fundação Getúlio Vargas.

Fico, C. (2008). A ditadura documentada: acervos desclassificados do Regime Militar Brasileiro. Acervo Revista do Arquivo Nacional, 21(2), 67-78, (jul/dez. 2008). Rio de Janeiro: Arquivo Nacional.

Glénisson, J. (1961). Iniciação aos estudos históricos. São Paulo: Difusão Européia do Livro.

Haguette, T. M. F. (1992). Metodologias qualitativas na sociologia. Petropolis, R.J: Vozes.

Halbwachs, M. (1990). A memória Coletiva. São Paulo: Vértice/Editora dos Tribunais.

Halbwachs, M. (1994). Les cadres sociaux de la mémoire. Paris: Éditions Albin Michel.

Ishaq, V., \& Franco, P. (2008). Os acervos dos Órgãos Federais de Segurança e Informação do regime militar no Arquivo Nacional. Acervo Revista do Arquivo Nacional, 21(2), 1328, (jul/dez. 2008). Rio de Janeiro: Arquivo Nacional.

Le Goff, J. (1996). História e Memória. Campinas, S.P: Editora da UNICAMP. 
Mainwaring, S. (1989). A Igreja católica e politica no Brasil (1965-1985). São Paulo: Editora Brasiliense.

Pollack, M. (1989). Memória, esquecimento, silêncio. Estudos Históricos, 2(3), 3-15. Rio de Janeiro: FGV.

Pollack, M. (1992). Memória e identidade social. Estudos Históricos, 5(10), 200-215. Rio de Janeiro: FGV.

Pomian, K. (2000). Memória. In Sistemática. Enciclopédia Einaudi, 42, 507-516. Edição Portuguesa. Imprensa Nacional - Casa da Moeda.

Portelli, A. (2001). História Oral como Gênero. Projeto História, (22). São Paulo.

Silva, A.M., Ribeiro, F., Ramos, J. \& Real, M.L. (2202). Arquivistica. Teoria e prática de uma ciência da informação. Lisboa: Ediçóes Afrontamento.

Thompson, P. (2002). História oral e contemporaneidade. História Oral-Revista da Associação Brasileira de História Oral, 5, 9-28. São Paulo: Associação Brasileira de História Oral. 